\title{
OCEAN COLOR PRODUCTS RETRIEVAL AND VALIDATION AROUND CHINA COAST WITH MODIS
}

\author{
L. Sun ${ }^{\mathrm{a}}$, M. Guo ${ }^{\mathrm{b}}, \mathrm{X}$. Wang ${ }^{\mathrm{b}}$

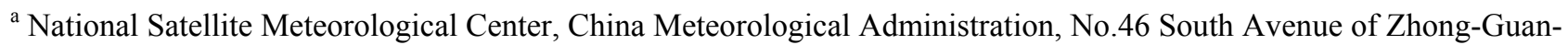 \\ Cun, Beijing 100081, China - sunling@nsmc.cma.gov.cn \\ ${ }^{\mathrm{b}}$ National Satellite Ocean Application Service, National Oceanic Administration, No.8 Da-Hui-Si Road, Beijing \\ 100081, China - (gmh,xmwang)@mail.nsoas.gov.cn
}

KEY WORDS: Atmosphere, Correction, Sea, Retrieval, Algorithms, Performance, Satellite, Optical

\begin{abstract}
:
Waters along China coast are very turbid with high concentrations of suspended sediment nearly all the time, especially at the Hangzhou Bay, the Yangtze River estuary and the shoal along Jiangsu province. In these turbid and optically complex waters, the standard MODIS ocean color products tend to have invalid values. Because the water-leaving radiances in the near-infrared (NIR) are significant resulting from the strong scattering of suspended particles, the standard MODIS atmospheric correction algorithm often gets no results or produces significant errors. And because of the complex water optical properties, the OC 3 model used in the standard MODIS data processing tends to get extremely high chlorophyll-a (Chl-a) concentrations. In this paper, we present an atmospheric correction approach using MODIS short wave infrared (SWIR) bands based on the fact that water-leaving radiances are negligible in the SWIR region because of the extreme strong absorption of water even in turbid waters. A regional Chl-a concentration estimation model is also constructed for MODIS from in situ data. These algorithms are applied to MODIS Aqua data processing in the China coastal regions. In situ data collected in the Yellow Sea and the East China Sea in spring and autumn, 2003 are used to validate the performance. Reasonably good results have been obtained. It is noted that water-leaving reflectance in the NIR bands are significant in waters along the China coast with high sediment loadings. The satellite derived and in-situ reflectance spectra can match in the turbid waters along China coast, and there is relatively good linear relationship between satellite derived and in-situ reflectance. The RMSE value of $\operatorname{Rrs}(\lambda)$ is 0.0031 for all the nine ocean color bands (412 to $869 \mathrm{~nm}$ ). The satellite-derived $\mathrm{Chl}-\mathrm{a}$ value is in the reasonable range and the root mean square relative error is $46.1 \%$.
\end{abstract}

\section{INTRUDUCTION}

There are some of the most highly turbid coastal waters in the world along the China coastal region, especially in Hangzhou Bay, the Yangtze River estuary and the shoal along Jiangsu province, with consistently high concentrations of suspended sediment and complex optical properties. The performance of standard MODIS ocean color processing is poor in this region. There remain some issues related to the atmospheric correction and water constituent concentration estimation, e.g., chlorophyll a (Chl-a). The sensor-derived water-leaving radiances at the blue bands (e.g., 412 and $443 \mathrm{~nm}$ ) are often biased low and sometimes even go negative, which often results from turbid waters with significant ocean radiance contributions at the nearinfrared (NIR) bands (Siegel et al., 2000). The sensor-derived Chl-a concentration is often highly overestimated as the result of both biased water-leaving reflectance spectrum and estimation model not suitable for these complex waters.

In the standard MODIS atmospheric correction, black ocean assumption at the two NIR bands (748 and $869 \mathrm{~nm}$ ) is adopted for the open ocean (Gordon and Wang, 1994; Gordon, 1997). However, due to the strong scattering of suspended particles, the water-leaving radiances in the NIR bands are significant for turbid waters. Based on the fact that water has much stronger absorption at the short wave infrared (SWIR) wavelengths than the NIR wavelengths, the water-leaving radiances are generally negligible at the SWIR bands even for very turbid ocean waters.

In the standard MODIS ocean color processing, the OC3 model is used for Chl-a concentration estimation ( $\mathrm{O}^{\prime}$ Reilly et al.,
1998). However, due to the local features of ocean optical properties, this model is not proper for the turbid China coastal waters. Regional model should be constructed.

In this paper, an atmospheric correction algorithm using SWIR bands and a regional Chl-a estimation model are presented for MODIS. The ocean color products derived from MODIS Aqua data using these algorithms are reported and validated with in situ data collected in the Yellow Sea and the East China Sea.

\section{RETRIEVAL ALGORITHMS}

\subsection{Atmospheric Correction Algorithm}

For the ocean-atmosphere system, the top-of-atmosphere (TOA) reflectance measured by the satellite sensor in a spectral band centred at a wavelength $\lambda, \rho_{t}(\lambda)$, can be written as a linear sum of various contributions (angular dependencies are omitted):

$$
\begin{aligned}
& \rho_{\mathrm{t}}(\lambda)=\left[\rho_{\mathrm{w}}(\lambda)+\rho_{\mathrm{wc}}(\lambda)+\rho_{\mathrm{g}}(\lambda)\right] \mathrm{T}_{\mathrm{g}}(\lambda) \mathrm{T}_{\mathrm{r}+\mathrm{a}}(\lambda)+\rho_{\mathrm{atm}}(\lambda) \\
& \rho_{\mathrm{atm}}(\lambda)=\left[\rho_{\text {mix }}(\lambda)-\rho_{\mathrm{r}}(\lambda)\right] \mathrm{T}_{\mathrm{g}}(\lambda)+\rho_{\mathrm{r}}(\lambda) \mathrm{T}_{\mathrm{g}}^{\prime}(\lambda)
\end{aligned}
$$

where $\rho_{\mathrm{w}}=$ water-leaving reflectance

$\rho_{\mathrm{wc}}=$ whitecap reflectance

$\rho_{\mathrm{g}}=$ sun glint reflectance

$\mathrm{T}_{\mathrm{g}}$, gaseous absorption transmittance

$\mathrm{T}_{\mathrm{g}}$ = gaseous absorption transmittance excluding water vapour 
$\mathrm{T}_{\mathrm{r}+\mathrm{a}}=$ scattering transmittance of the Rayleigh and aerosol mixing atmosphere

$\rho_{\text {atm }}=$ intrinsic atmospheric reflectance reaching the sensor

$\rho_{\text {mix }}=$ reflectance for the Rayleigh and aerosol mixing atmosphere not accounting for absorptive gases $\rho_{\mathrm{r}}=$ reflectance for a pure Rayleigh atmosphere not accounting for absorptive gases

None water-leaving effects are calculated and removed from $\rho_{t}$ to extract $\rho_{\mathrm{w}}$. $\rho_{\mathrm{r}}$ is calculated using look-up tables with angles and surface pressure (Sun et al., 2006). $\mathrm{T}_{\mathrm{g}}$ together with $\mathrm{T}_{\mathrm{g}}$ is calculated using formulas based on simulations with angles and gases amounts (Sun and Zhang, 2007). $\rho_{\mathrm{wc}}$ is estimated using an empirical model with wind speed (Koepke, 1984; Gordon, 1997). $\rho_{\mathrm{g}}$ is estimated using the Cox \& Munk model with wind and angles (Cox and Munk, 1954). $\mathrm{T}_{\mathrm{r}+\mathrm{a}}$ is calculated using lookup tables with certain aerosol model, aerosol optical thickness $\tau_{\mathrm{a}}$ and angles (Sun, 2005). To determine $\rho_{\text {mix }}$, mainly the aerosol contribution because $\rho_{\mathrm{r}}$ can be calculated in advance, $\tau_{\mathrm{a}} \leftarrow \rightarrow \gamma$ $\left(\gamma=\rho_{\text {mix }} / \rho_{\mathrm{r}}\right)$ lookup tables with various aerosol models and angles are used (Sun and Guo, 2006; Antoine and Morel, 1999). Ten candidate aerosol models which are mainly based on four basic component mixing are adopted. The aerosol scattering phase function $\mathrm{P}_{\mathrm{a}}(\Theta)$ and normalized aerosol optical thickness $\Delta \tau_{\mathrm{a}}$ are shown in Figure 1.

The water-leaving reflectance at two SWIR bands (centered at 1240 and $2130 \mathrm{~nm})$ are assumed zeros. Thus, $\gamma(1240)$ and $\gamma(2130)$ are obtained from $\rho_{\mathrm{t}} . \tau_{\mathrm{a}}(2130)_{\mathrm{i}}$ for 10 aerosol models are calculated using $\tau_{\mathrm{a}} \leftarrow \rightarrow \gamma$ lookup tables, and $\tau_{\mathrm{a}}(\lambda)_{\mathrm{i}}$ are extrapolated with the normalized optical thickness $\Delta \tau_{\mathrm{a}}(\lambda)_{\mathrm{i}}$, and $\gamma(1240)_{\mathrm{i}}$ are reversely calculated using $\tau_{\mathrm{a}} \leftarrow \rightarrow \gamma$ lookup tables. Then, two aerosol models (represented with i1 and i2) most similar to the actual one are selected according to $\gamma(1240)_{\mathrm{i} 1}<\gamma(1240)<\gamma(1240)_{\mathrm{i} 2}$, and the mixing ratio $\mathrm{X}$ for interpolation between two aerosols is calculated as $[\gamma(1240)$ $\left.\gamma(1240)_{\mathrm{i} 1}\right] /\left[\gamma(1240)_{\mathrm{i} 2}-\gamma(1240)_{\mathrm{i} 1}\right]$. And then, for the visible and NIR bands, $\gamma(\lambda)_{\mathrm{i} 1}$ and $\gamma(\lambda)_{\mathrm{i} 2}$ are calculated from $\tau_{\mathrm{a}}(\lambda)_{\mathrm{i} 1}$ and $\tau_{\mathrm{a}}(\lambda)_{\mathrm{i} 2}$, and $\gamma(\lambda)$ is estimated as $(1-\mathrm{X}) \gamma(\lambda)_{\mathrm{i} 1}+\mathrm{X} \gamma(\lambda)_{\mathrm{i} 2}$, and $\rho_{\text {mix }}(\lambda)$ can then be calculated. Till now, $\rho_{\mathrm{w}}$ can be calculated from Equation (1).
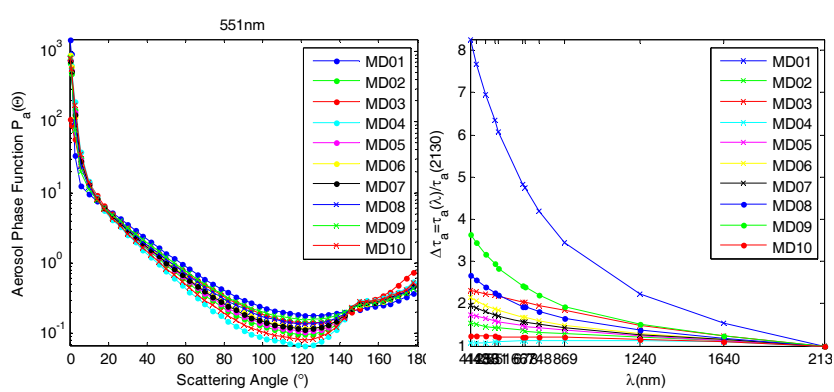

Figure 1. Aerosol scattering phase function for $551 \mathrm{~nm}$ band (a) and normalized aerosol optical thickness (b)

\subsection{Chlorophyll-a Concentration Estimation Model}

In situ chlorophyll-a concentrations were measured using HPLC method, and remote sensing reflectance spectra $\mathrm{R}_{\mathrm{rs}}(\lambda)$ from 350 to $1050 \mathrm{~nm}$ were derived from ASD measurements using above water method during the spring and fall of 2003 in the Yellow Sea and the East China Sea (Tang et al., 2004). Using the 76 data collected in fall (the maximum, minimum and mean Chl-a values are $35.9,0.2$ and $2.2 \mathrm{mg} / \mathrm{m}^{3}$, respectively), an empirical model is constructed as follows:

$$
\begin{aligned}
\log _{10}(\mathrm{Chl}-\mathrm{a})= & 0.118445-3.05761 \log _{10}\left(\mathrm{X}_{\mathrm{c}}\right) \\
& +3.098626 \log _{10}{ }^{2}\left(\mathrm{X}_{\mathrm{c}}\right) \quad\left(\mathrm{R}^{2}=0.73\right)
\end{aligned}
$$

where $\quad \mathrm{R}_{\mathrm{rs}}=$ water remote sensing reflectance

The model has been tested with in situ $\mathrm{R}_{\mathrm{rs}}$ data. The root mean square relative error is $45.3 \%$ for the 76 data used in model construction. When 83 data in spring (the maximum, minimum and mean Chl-a values are 15.2, 0.4 and $2.6 \mathrm{mg} / \mathrm{m}^{3}$, respectively) are used for model testing, the root mean square relative error is $64.9 \%$. Figure 2 provides the comparison between in situ Chl-a concentrations and model estimated Chl-a values from in situ $R_{\mathrm{rs}}$. The results of linear fits for the data in fall and spring are also shown in the plot. The linear relationships between model estimated and in situ Chl-a are not very obvious with low correlation coefficient $\mathrm{R}^{2}$.

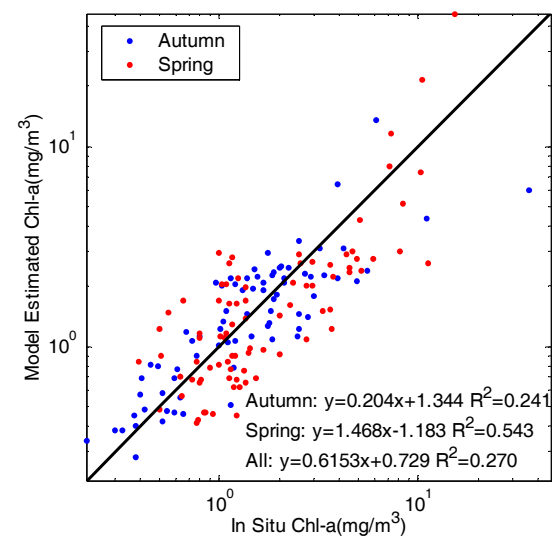

Figure 2. Model derived Chl-a values compared with in situ Chl-a concentrations

\section{OCEAN COLOR PRODUCTS AROUND CHINA COAST}

\subsection{MODIS Ocean Color Products}

MODIS Aqua data have been processed for the China coastal region using the SWIR atmospheric correction and Chl-a algorithm described in section 2. For the data processing, the MOD35 products have been used for cloud masking. Ancillary data including wind, ozone and water vapour are from climatology dataset. The derived products include waterleaving reflectance, chlorophyll-a concentration, and aerosol optical thickness (AOT), etc.

Figure 3a provides a MODIS Aqua true color image around the China coast on October 19, 2003. This image shows the very turbid waters along the China coast (brownish yellow to green in color), particularly the Hangzhou Bay, the Yangtze River estuary, and the shoal along Jiangsu province with extremely high sediment concentrations. Figures $3 b-3 h$ are examples of the de- 
rived ocean color products corresponding to the MODIS data shown in Figure 3a. Figures $3 \mathrm{~b}-3 \mathrm{~h}$ are the images of waterleaving reflectance $\rho_{\mathrm{w}}(\lambda)$ at wavelengths $443,488,551,667$ and $869 \mathrm{~nm}$, chlorophyll-a concentration (Chl-a), and aerosol optical thickness at $869 \mathrm{~nm}$ band $\tau_{\mathrm{a}}(869)$, respectively. Values of $\rho_{\mathrm{w}}(\lambda)$ from 443 to $667 \mathrm{~nm}$ bands (Figure $3 \mathrm{~b}$ to $3 \mathrm{e}$ ) are scaled linearly from 0.0 to 0.15 , while $\rho_{\mathrm{w}}(869)$ (Figure $3 \mathrm{f}$ ) is scaled linearly from 0.0 to 0.05 . Value of Chl-a (Figure $3 \mathrm{~g}$ ) is scaled logarithmically from 0.09 to $30(\mathrm{mg} / \mathrm{m} 3)$. Value of $\tau_{\mathrm{a}}(869)$ (Figure $3 \mathrm{~h}$ ) is scaled from 0.0 to 0.6 .
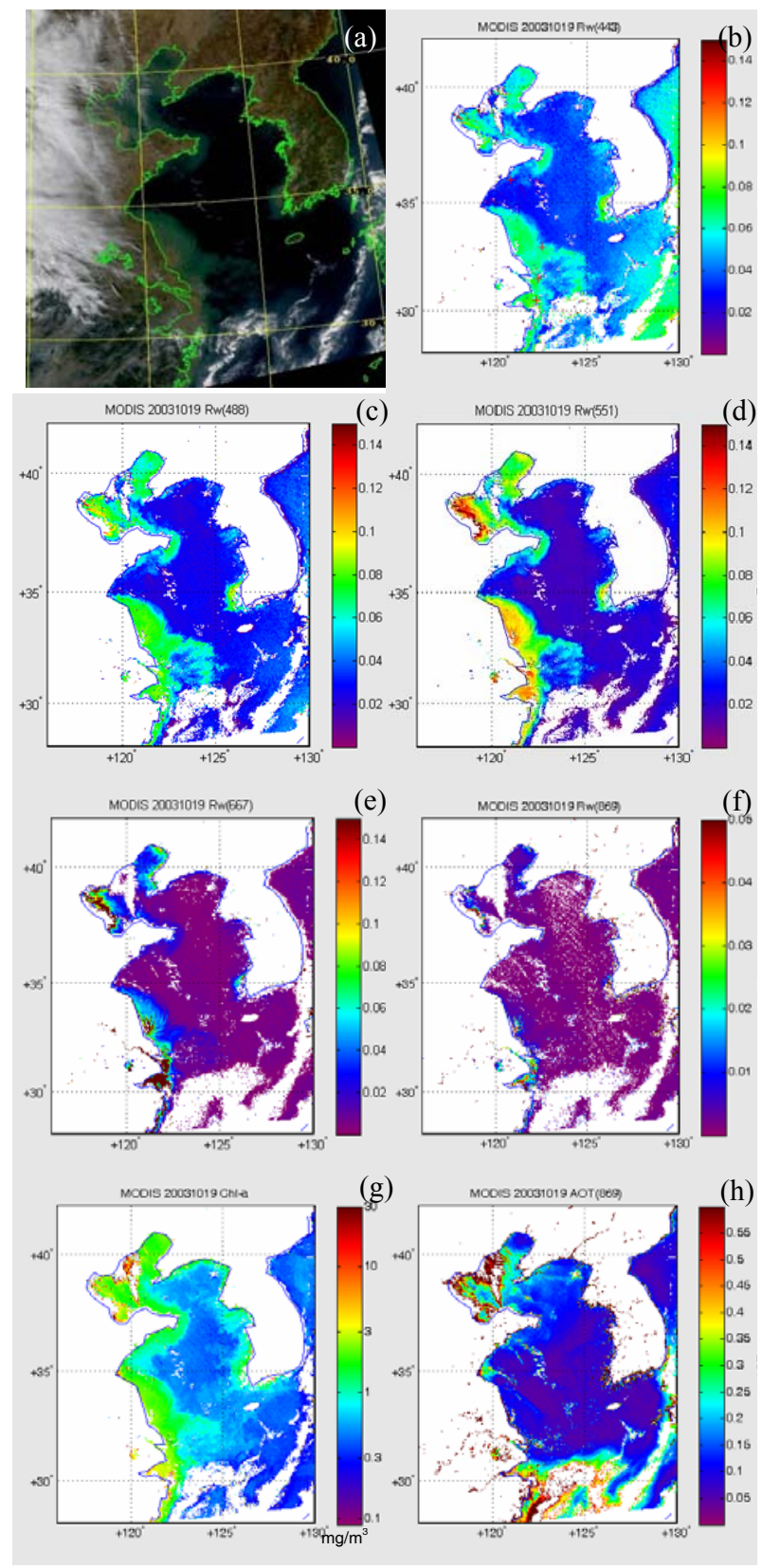

Figure 3. MODIS Aqua products on October 19, 2003 around the China coast for (a) true color image, (b-f) $\rho_{\mathrm{w}}(\lambda)$ at 443,488 , 551, 667 and $869 \mathrm{~nm}$ bands, respectively, (g) Chl-a, and (h) $\tau_{\mathrm{a}}(869)$

It can be seen that, along the China coastal region, the MODIS derived $\rho_{\mathrm{w}}(\lambda)$ value increases from blue to green. The extremely high value in $667 \mathrm{~nm}$ (Figure 3e) with brownish red color is due to the sensor saturation in this band. The NIR ocean contributions are significant, especially at the Hangzhou Bay, and some region in the Yangtze River estuary and the shoal along Jiangsu province. The MODIS-derived Chl-a values are in the reasonable range. And the results in Figure 3 show no obvious correlations between the derived oceanic properties $\left(\rho_{\mathrm{w}}(\lambda)\right.$ and $\left.\mathrm{Chl}-\mathrm{a}\right)$ and atmospheric property, e.g., $\tau_{\mathrm{a}}(869)$.

\subsection{MODIS Products Compared with In Situ Data}

The remote sensing reflectance spectra $\operatorname{Rrs}(\lambda)$ derived from in situ measurements during the spring and fall of 2003 in the Yellow Sea and the East China Sea are taken to be compared with those from MODIS-derived $\rho_{\mathrm{w}}(\lambda)$ with the conversion of $\operatorname{Rrs}(\lambda)=\rho_{\mathrm{w}}(\lambda) / \pi$. Figure 4 provides four examples of these comparisons. The location in latitude and longitude and time difference between MODIS and in situ measurements are indicated in each plot. The in situ data were collected at the locations indicated in Figure $3 \mathrm{~b}$. The MODIS data were the average of pixels within $\pm 0.015^{\circ}$ centred at the in situ data location.

It shows in Figure 4 that the SWIR atmospheric correction performs reasonably well for these turbid waters. The in situ data shows high remote sensing reflectance values in NIR bands (748 and $869 \mathrm{~nm})$, i.e., the NIR $\operatorname{Rrs}(\lambda)$ values range from 0.0006 to 0.003 , while the values at site HD02 are relatively low. For these cases, the MODIS-derived $\operatorname{Rrs}(\lambda)$ can match well with the in situ data except for site HD02 with underestimations at 667 to $748 \mathrm{~nm}$ bands.
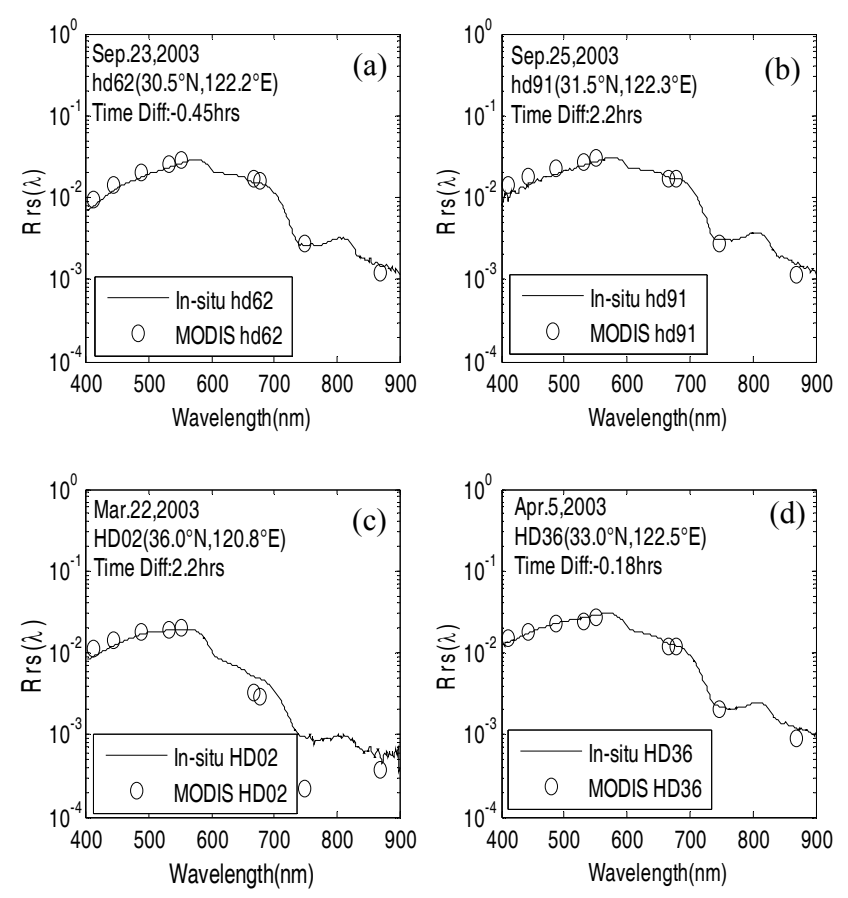

Figure 4. MODIS derived remote sensing reflectance spectra compared with those from in situ data acquired on (a)

September 23, 2003, (b) September 25, 2003, (c) March 22, 2003, and (d) April 5, 2003

Figure 5 shows comparisons between the in situ and MODIS derived $\operatorname{Rrs}(\lambda)$ values at the eight MODIS bands. In situ data 
acquired within \pm 6 hours centred at the MODIS measurement time are included with a total of 20 match-ups. Although there are some noises, the results in Figure 5 show a relatively good linear relationship between MODIS and in situ $\operatorname{Rrs}(\lambda)$. The slope of the linear fit for all the eight bands is 1.093 , the intercept is 0.000702 and the correlation coefficient $R^{2}$ is 0.923 . The results of linear fits for eight bands of 412, 443, 488, 531, 551, 667, 678, 748 and $869 \mathrm{~nm}$ are also shown in the plot, indicating more noise at the 412,443 and $748 \mathrm{~nm}$ band. The MODIS derived $\operatorname{Rrs}(\lambda)$ tends to be overestimated at 412 and $443 \mathrm{~nm}$ bands which may be subject to the radiative transfer precision and improper aerosol models. The RMSE values of $\operatorname{Rrs}(\lambda)$ are $0.0054,0.0054,0.0032,0.0029,0.0036,0.00095,0.00094$, 0.0010 and 0.0004 for $412,443,488,531,551,667,678,748$ and $869 \mathrm{~nm}$ bands, respectively. The RMSE for all dataset is 0.0031 .

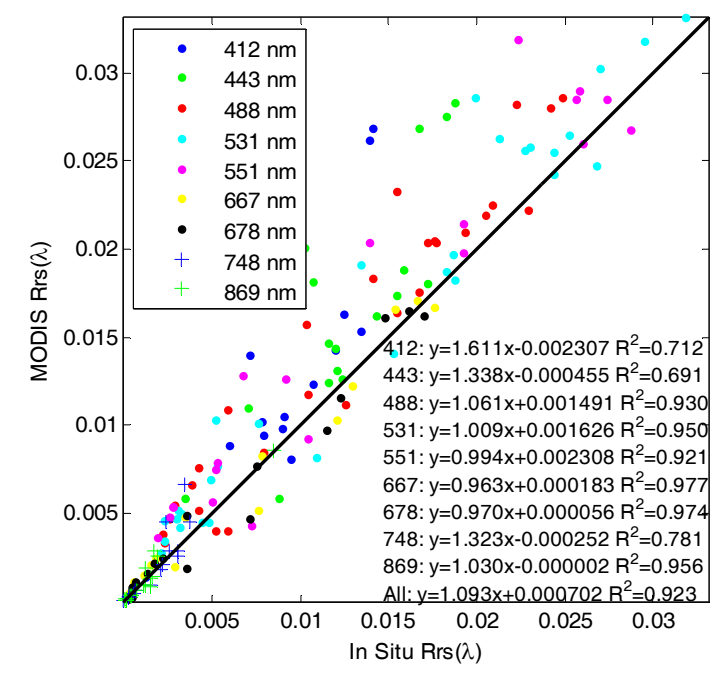

Figure 5. MODIS derived remote sensing reflectance values compared with in situ data for the bands of 412, 443, 488, 531, $551,667,678,748$ and $869 \mathrm{~nm}$

The HPLC measured in situ chlorophyll-a concentration collected during the spring and fall of 2003 in the Yellow Sea and the East China Sea are taken to be compared with the MODIS-derived Chl-a. The root mean square relative errors are $45.5 \%$ and $47.1 \%$ for data in fall and spring, respectively. The root mean square relative error for all dataset is $46.1 \%$. Figure 6 provides the comparison between the in situ and MODIS derived Chl-a values. The results of linear fits for the data in fall and spring are also shown in the plot. Similar with the result of model estimation from in situ Rrs shown in Figure 2, there is not a good linear relationship between MODIS derived and in situ Chl-a.

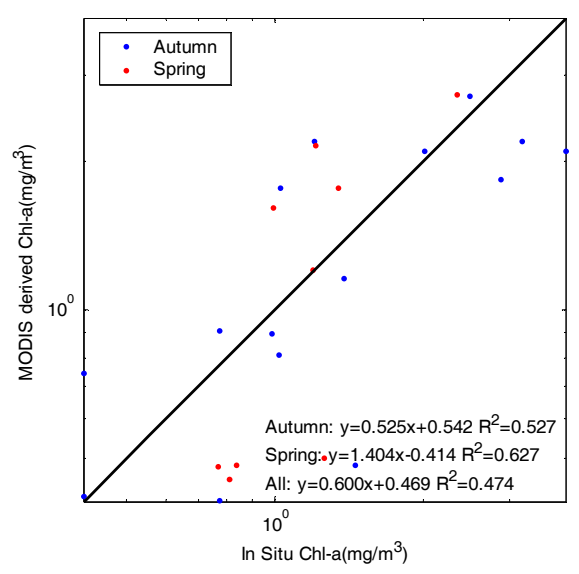

Figure 6. MODIS derived Chl-a values compared with in situ Chl-a concentrations

\section{CONCLUSIONS}

We have presented the SWIR atmospheric correction and Chl-a concentration estimation model for MODIS ocean color processing and used them to derive the MODIS Aqua waterleaving reflectance spectra and Chl-a along the China coastal region. In these turbid and optically complex waters, the standard MODIS ocean color products tend to have invalid values. By image analysis and comparing our MODIS derived ocean color products with those from in situ measurements collected in the Yellow Sea and the East China Sea, reasonably good results have been obtained. It is obvious that along the China coast with high sediment loadings, water-leaving reflectance in the NIR bands is significant. The satellite derived and in-situ reflectance spectra can match in the turbid waters along China coast, and there are relatively good linear relationship between satellite derived and in-situ reflectance in most of ocean color bands. The RMSE values of $\operatorname{Rrs}(\lambda)$ are $0.0054,0.0054,0.0032,0.0029,0.0036,0.00095,0.00094$, 0.0010 and 0.0004 for $412,443,488,531,551,667,678,748$ and $869 \mathrm{~nm}$ bands, respectively, and 0.0031 for all dataset. The satellite-derived Chl-a values are in the reasonable range and the root mean square relative error is $46.1 \%$.

\section{REFERENCES}

Antoine, D., and Morel, A., 1999. A multiple scattering algorithm for atmospheric correction of remotely sensed ocean color (MERIS instrument): principle and implementation for atmospheres carrying various aerosols including absorbing ones. Int. J. Remote Sens., 20(9), pp. 1875-1916.

Cox, C., and Munk, W., 1954. Measurements of the roughness of the sea surface from photographs of the Sun's glitter. J. Opt. Soc. Am., 44(11), pp. 838-850.

Gordon, H. R., 1997. Atmospheric correction of ocean color imagery in the earth observing system era. J. Geophys. Res., 102(D14), pp. 17081-17106.

Gordon, H. R., and Wang, M., 1994. Retrieval of water-leaving radiance and aerosol optical thickness over the oceans with SeaWiFS: a preliminary algorithm. Appl. Opt., 33(3), pp. 443452. 
Koepke, P., 1984. Effective reflectance of oceanic whitecaps. Appl. Opt., 23(11), pp. 1816-1824.

O'Reilly, J. E., Maritorena, S., and Mitchell, B. G., 1998. Ocean color chlorophyll algorithms for SeaWiFS. J. Geophys. Res., 103(C11), pp. 24937-24953.

Siegel, D. A., Wang, M., and Maritorena, S., 2000. Atmospheric correction of satellite ocean color imagery: The black pixel assumption. Appl. Opt., 39(21), pp. 3582-3591.

Sun, L., 2005. Atmospheric Correction and Water Constituent Retrieval for HY-1A CCD. PhD thesis, Institute of Oceanology, Chinese Academy of Science, Qingdao, China. (in Chinese)

Sun, L., and Guo, M., 2006. Atmospheric correction for HY1A CCD in Case 1 waters. In: Proceedings of SPIE, Remote Sensing of the Environment: 15th National Symposium on Remote Sensing of China, Guiyang, China, Vol. 6200, pp. 2031.

Sun, L., and Zhang, J., 2007. Analysis of influence of gaseous absorption on "HY-1A" CCD data: simulation and correction for Rayleigh scattering. ACTA Oceanologica Sinica, 29(3), pp. 137-145. (in Chinese)

Sun, L., Zhang, J., and Guo, M., 2006. Rayleigh lookup tables for HY-1A CCD data processing. J. Remote Sens, 10(3), pp. 306-311. (in Chinese)

Tang, J., Wang X., Song, Q., Li, T., Chen, J., Huang, H., and Ren, J., 2004. The statistic inversion algorithms of water constituents for Yellow Sea \& East China Sea. ACTA Oceanologica Sinica, 23(4), pp. 617-626.

\section{ACKNOWLEDGEMENTS}

This research was supported by the National Natural Science Foundation of China (project 40606043) and National Basic Research Program of China (project 2006CB40370) and NewTech Popularization Program of China Meteorological Administration (project CMATG2006Z02). 
